\title{
PRESSÃO DE PRECONSOLIDAÇÃO COMO FERRAMENTA DE ANÁLISE DA SUSTENTABILIDADE ESTRUTURAL DE CLASSES DE SOLOS COM DIFERENTES USOS ${ }^{(1)}$
}

\author{
Piero Iori ${ }^{(2)}$, Reginaldo Barboza da Silva ${ }^{(3)}$, Moacir de Souza Dias Júnior ${ }^{(4)}$ \& José \\ Maria de Lima ${ }^{(5)}$
}

\begin{abstract}
RESUMO
O principal problema ambiental causado pelo uso do solo em áreas de preservação permanente longitudinais aos rios é a supressão da mata ciliar. $O$ tipo e a intensidade desse uso alteram a estrutura do solo e comprometem as funções físicas dessas áreas, principalmente próximo aos cursos d'água. $O$ objetivo deste trabalho foi avaliar a sustentabilidade estrutural, a partir do ensaio de compressão uniaxial, de três classes de solo (Cambissolo Háplico, Argissolo Amarelo e Gleissolo Háplico) e o impacto de diferentes tipos de usos do solo - não permitido pela legislação ambiental - de áreas de preservação permanente na sub-bacia do rio Ribeira de Iguape, SP. Foram delimitadas na área experimental três classes de solo: Cambissolo, Argissolo e Gleissolo. Numa primeira etapa, compararam-se as três classes de solos sob mata nativa e sob pastagem. Na segunda, avaliou-se a influência de diferentes tipos de uso do solo - cultivo de banana, pastagem degradada, uso silvipastoril e mata nativa - sobre a estrutura de um Cambissolo. A pressão de preconsolidação mostrouse ferramenta capaz de identificar a degradação nos solos. $O$ uso do solo nas áreas de preservação permanente altera a pressão de preconsolidação do solo, causando sua degradação estrutural, colocando em risco a sustentabilidade das terras, e não deve ser permitido. $O$ Gleissolo mostrou maiores valores de pressão de preconsolidação em função de teores crescentes de água e, portanto, maior capacidade de suporte de carga em relação ao Cambissolo e Argissolo. $O$ cultivo de banana foi o tipo de uso que mais degradou os solos das áreas de preservação permanente.
\end{abstract}

Termos de indexação: capacidade de suporte de carga, modelagem, Vale do Ribeira.

(1) Recebido para publicação em 29 de março de 2011 e aprovado em 25 de junho de 2012.

(2) Engenheiro-Agrônomo, Doutorando, Departamento de Ciência do Solo (DCS), Universidade Federal de Lavras - UFLA, Campus Universitário, Caixa Postal 3037. CEP 37200-000 Lavras (MG). E-mail: pieroiori@hotmail.com

(3) Professor, Universidade Estadual Paulista, Campus Experimental de Registro, Rua Nelson Brihi Badur, 430. CEP 11900-000 Registro (SP). E-mail: rbsilva@registro.unesp.br

(4) Professor Adjunto, DCS, UFLA. Bolsista CNPq e Pesquisador Mineiro da FAPEMIG. E-mail: msouzadj@dcs.ufla.br

(5) Professor Associado, DCS, UFLA. Bolsista CNPq. E-mail: jmlima@dcs.ufla.br 


\title{
SUMMARY: PRECONSOLIDATION PRESSURE AS A TOOL FOR SUSTAINABILITY ANALYSIS OF SOIL STRUCTURE OF SOIL CLASSES UNDER DIFFERENT USES
}

\begin{abstract}
The main environmental problem caused by land use in permanent protection areas along river banks is the removal of the primary vegetation. Depending on the type and intensity of use, the soil structure of this river banks can be altered and the physical functions modified, especially near the watercourses. The purpose of this study was to evaluate the structural sustainability of three classes of river bank soil using the preconsolidation pressure measurement and thereby assess the impact of these different land uses on river bank stability in the sub-basin of the Ribeira Valley, SP. The experimental area consists of three soil types, Cambisol, Ultisol and Gley soils. In the first analysis, the preconsolidation pressure of the three soil types under native forest and pasture was compared. The second analysis evaluated the influence of different land uses; banana cultivation, degraded pasture, native forest and silvopastoral use on the structure of the Cambisol. Our result showed that preconsolidation pressure values are useful tools to identify soil degradation in these protected areas, since the changing values adequately represent degradation tendencies. The land use in the permanent protection areas resulting in changed preconsolidation pressure tends to cause structural degradation, threatening the sustainability and stability of the land, and should not be allowed. The Gleysol showed higher values of preconsolidation pressure as a function of increasing water levels and, therefore, greater load support capacity than the Cambisol and Ultisol. Banana was the crop that degraded the soils in the permanent preservation areas most.
\end{abstract}

Index terms: load support capacity, modeling, Vale do Ribeira.

\section{INTRODUÇÃO}

O solo, um recurso natural básico, é renovável, se conservado ou utilizado corretamente (Primavesi, 2002). Entretanto, a falta de conhecimentos tecnológicos para utilização adequada por parte dos agricultores e pecuaristas, entre outros, tem favorecido sua degradação estrutural, acelerando o processo da erosão - uma das mais nefastas consequências que comprometem diretamente os recursos hídricos.

A utilização de áreas de preservação permanente longitudinais ao rio Ribeira de Iguape para fins agropecuários é vedada segundo o Código Florestal: "área ao longo dos rios ou de qualquer curso d'água desde o seu nível mais alto em faixa marginal cuja largura mínima será de 200 metros para os cursos d'água que tenham de 200 a 600 metros de largura coberta ou não por vegetação nativa, com a função ambiental de preservar os recursos hídricos" (Lei n ${ }^{\circ}$ 4.771/1965) - redação dada pela Lei no 7.803/1989. Essas áreas devem ser mantidas intocadas e, caso estejam degradadas, deve-se proceder à sua imediata recuperação.

Apesar da proibição de utilização das APPs, observa-se no campo que parte dessas áreas está sendo usada para fins agropecuários. A falta de conhecimento dos impactos ambientais causados pelas explorações dessas áreas marginais aos rios (APPs) coloca em risco a sustentabilidade das terras e dos recursos hídricos da bacia do rio Ribeira de Iguape. Acrescenta-se ainda que o uso indevido desses solos e a falta de tecnologias e de opções de manejo apropriados a esses pedoambientes agrícolas e naturais alteram os atributos físicos, hídricos e mecânicos do solo e, por conseguinte, causam sua degradação estrutural. Portanto, trabalhos com a finalidade de identificar e estudar essas faixas das APPs longitudinais ao rio Ribeira de Iguape podem evidenciar a degradação do solo.

O estabelecimento de índices de qualidade do solo é necessário para monitorar mudanças na sustentabilidade e a qualidade ambiental em relação ao manejo agrícola (Doran \& Parkin, 1996). É conhecido que diferentes tipos de uso da terra alteram de maneira diferenciada importantes atributos dos solos. A constante preocupação com a sustentabilidade dos ecossistemas torna necessário o monitoramento desses atributos, para que sejam estabelecidos tipos de manejo do solo que garantam sua sustentabilidade (Lopes, 2007). A sustentabilidade de uso do solo pode ser estimada por avaliações de indicadores relacionados a processos e propriedades. Os diferentes indicadores devem ser cuidadosamente escolhidos em relação aos objetivos e devidamente analisados e interpretados (Bochner, 2007). Indicadores físicos, químicos e biológicos do solo são capazes de prover uma medida das condições do solo, assim como a magnitude e direção dos processos predominantes (Lal, 1999).

Embora existam vários atributos dos solos que possam ser usados como indicadores, nem todos atendem a alguns critérios, como sensibilidade às alterações de manejo, integração com as funções do 
solo, praticidade e baixo custo de determinação (Bochner, 2007). A pressão de preconsolidação $\left(\sigma_{p}\right)$ tem mostrado-se uma importante alternativa, pois foi considerada por Dias Júnior (1994), um indicador da máxima pressão aplicada ao solo no passado e um indicador de suscetibilidade do solo à compactação. A importância do conhecimento da pressão de preconsolidação é amplamente reconhecida, por auxiliar na introdução de sistemas conservacionistas de manejo (Römkens \& Miller, 1971). Oliveira et al. (2003) e Silva et al. (2010a) relataram a importância da utilização de informações sobre a pressão de preconsolidação para o manejo racional, por permitir a predição do comportamento compressivo do solo. A utilização do ensaio de compressão uniaxial vem sendo largamente pesquisada na avaliação dos diversos efeitos da compactação do solo (Dias Júnior \& Pierce, 1995; Silva et al., 2003; Araújo-Júnior et al., 2008; Ajayi et al., 2010; Severiano et al., 2010a), sendo considerado, portanto, um método muito difundido (Dias Júnior et al., 2004).

Desse modo, as hipóteses deste trabalho foram que a pressão de preconsolidação é uma ferramenta eficiente para a análise da sustentabilidade estrutural dos solos, que a utilização de solos para fins agropecuários em APP é danosa à sustentabilidade ambiental e não deve ser permitida e, por fim, que os usos a que os solos são submetidos em APPs alteram sua pressão de carga e contribuem para sua degradação.

Pesquisas que objetivem avaliar a qualidade dos solos de APPs podem detectar tendências de mudanças que são mensuráveis num período relativamente longo e elucidar alternativas de correção da degradação desses solos. Contudo, ainda é incerto o impacto dos usos e manejos agrícolas utilizados nas APPs, especialmente na região do Vale do Ribeira. Assim, objetivou-se neste trabalho, a partir do ensaio de compressão uniaxial, avaliar a sustentabilidade estrutural de três classes de solo (Cambissolo Háplico, Argissolo Amarelo e Gleissolo Háplico) e o impacto de diferentes tipos de usos do solo - não permitido pela legislação ambiental - de áreas de preservação permanente na sub-bacia do rio Ribeira de Iguape, SP.

\section{MATERIAL E MÉTODOS}

O trabalho foi realizado na sub-bacia rio Ribeira de Iguape, em área de proteção permanente localizada longitudinalmente ao rio Ribeira de Iguape, inclusa no município de Registro (SP), com latitude de $24^{\circ} 26^{\prime}$ $\mathrm{S}$, longitude de $47^{\circ} 49^{\prime} \mathrm{W}$ e altitude em torno de $25 \mathrm{~m}$. O clima da região, de acordo com Köppen, citado por Silva et al. (2010b), é o Af, tropical úmido, com transição para o $\mathrm{Cfa}$, com precipitação pluvial média anual de $1.700 \mathrm{~mm}$.

Este trabalho é um estudo de caso, com a finalidade de identificar e estudar as faixas das APPs, longitudinais ao rio Ribeira de Iguape, utilizadas para fins agropecuários. Para isso, foram delimitadas na área experimental três classes de solo: Cambissolo Háplico, Argissolo Amarelo e Gleissolo Háplico (Embrapa, 2006). Primeiramente, foram comparadas as três classes de solos sob mata nativa (Cambissolo MCX, Argissolo - MPA e Gleissolo - MGX) e sob pastagem (Cambissolo - PCX, Argissolo - PPA e Gleissolo - PGX). Numa segunda etapa, foram comparados os diferentes tipos de uso do solo (cultivo de banana - CB, pastagem degradada - PD, uso silvipastoril - UP e mata nativa MCX) em um Cambissolo Háplico. Em cada condição, a amostragem foi realizada em malha irregular, totalizando 20 pontos, na profundidade de 0 a $5 \mathrm{~cm}$.

A caracterização do solo (Quadro 1) foi realizada por meio da avaliação da granulometria e da argila dispersa em água, pelo método da pipeta (Day, 1965); da densidade do solo, pelo método do anel volumétrico; do índice de floculação e do teor de matéria orgânica (Embrapa, 1997); e da densidade de partículas, pelo método do picnômetro (Blake \& Hartge, 1986).

A avaliação da sustentabilidade estrutural do solo foi feita por meio do ensaio de compressão uniaxial, utilizando um consolidômetro automático com interação homem/máquina (IHM), modelo CNTAIHM/BR-001/07, desenvolvido por Silva et al. (2007). Os níveis de pressão aplicados ao corpo-de-prova foram: $25,50,100,200,400,800$ e $1.600 \mathrm{kPa}$, observando-se a pressuposição de Taylor (1948), que define a deformação máxima de até $90 \%$ do corpo-de-prova, para cada nível de pressão.

Por meio do software CA LINKER ${ }^{\odot}$, desenvolvido por Silva \& Masquetto (2009), os valores de pressão e deformação foram devidamente tratados e plotados em um gráfico, obtendo-se, assim, a curva de compressão do solo (densidade do solo em função do logaritmo das pressões aplicadas). A partir da curva de compressão, foi estimada a $\sigma_{\mathrm{p}}$, observando a sugestão dos métodos $\mathrm{M}_{1}$ e $\mathrm{M}_{3}$, propostos por Dias Júnior \& Pierce (1995).

Para elaboração dos modelos de capacidade de suporte de carga do solo (MCSC), os valores de $\sigma_{\mathrm{p}}$ foram plotados em função da umidade volumétrica $(\theta)$ a que cada amostra foi submetida e, posteriormente, ajustados ao modelo $\sigma_{\mathrm{p}}=10^{(\mathrm{a}+\mathrm{b} \theta)}$, proposto por Dias Júnior (1994). Para elaboração desses modelos, foram utilizadas 15 amostras indeformadas provenientes das três classes de solo, coletadas em área de mata nativa.

$\mathrm{Na}$ avaliação do impacto dos diversos usos do solo foi utilizado o método de Dias Júnior et al. (2005), que consiste na divisão desses modelos em três "regiões" (Figura 1). Pontos na região "a" indicam que há compactação adicional; na região "b", que não ocorreu compactação adicional do solo, porém há tendência de que venha a ocorrer se não for respeitada a capacidade de suporte de carga do solo; e na região "c", ausência de compactação do solo.

Para avaliar a eventual compactação do solo desses locais, as amostras indeformadas foram saturadas por 
capilaridade com água destilada e equilibradas a $13 \%$ de umidade (baixa umidade) e na tensão de $4 \mathrm{kPa}$ (alta umidade). A tensão de $4 \mathrm{kPa}$ foi escolhida a fim de se conhecer o comportamento do solo nas épocas mais úmidas, ou seja, quando o teor de água está acima da capacidade de campo. Para Baver et al. (1972), a compactação máxima ocorre quando os solos estão nessa condição de umidade, o que diminui a coesão e eleva a lubrificação entre as partículas do solo. Como resultado, o solo é fluido o suficiente para facilitar a compactação. A umidade de $13 \%$ foi escolhida buscando simular o comportamento do solo nas épocas mais secas, comuns na região de estudo em determinados momentos do ano (Silva et al., 2009).

As análises foram realizadas no Laboratório de Física e Mecânica do Solo da Universidade Estadual Paulista (UNESP), campus experimental de Registro, e no Laboratório de Física do Departamento de Ciência do Solo da Universidade Federal de Lavras (UFLA). Mediante o uso do programa estatístico Sisvar (Ferreira, 2000), os dados foram inicialmente avaliados pela análise de variância e teste $\mathrm{F}$, considerando os tratamentos de uso do solo como fatores de variação. A comparação entre as médias, quando o valor de $\mathrm{F}$ foi significativo, foi feita pela barra de erros do intervalo de confiança de $95 \%$, por ser mais adequada, segundo Paes (2008), quando se trata de fazer inferências sobre as médias. A construção dos gráficos e a estimativa da correlação de Pearson entre as variáveis foram realizadas por meio da versão demonstrativa do aplicativo Sigma Plot 11.0 (Systat Software Inc $\left.{ }^{\circledR}\right)$.

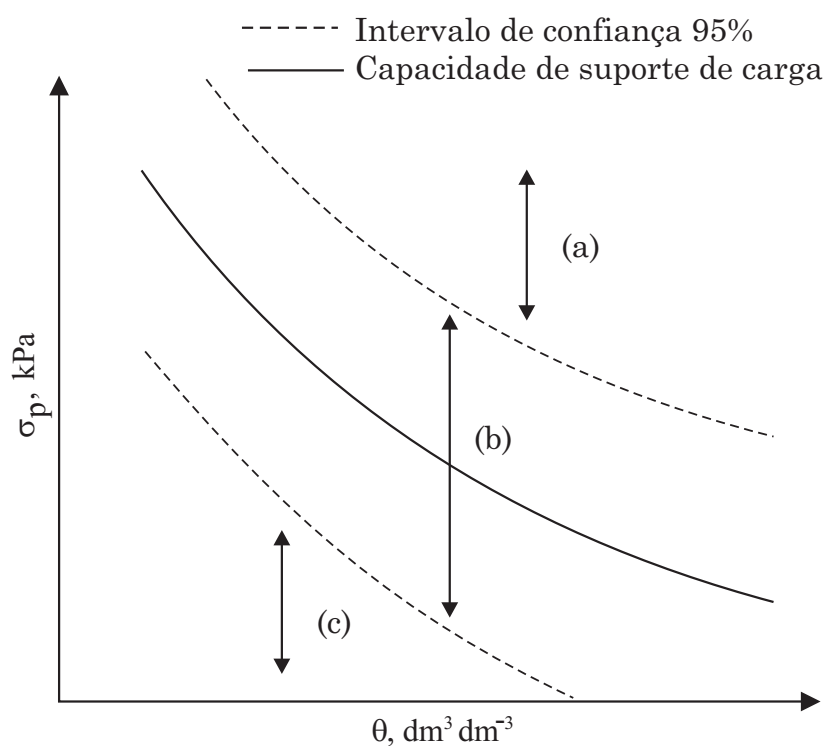

Figura 1. Modelo de capacidade de suporte de carga do solo, com as três "regiões" de análise da compactação. Região "a": com compactação; "b": sem compactação, mas com tendência a compactar; e "c": sem compactação. Modificado de Dias Júnior et al. (2005).

\section{RESULTADOS E DISCUSSÃO}

Os maiores valores (Quadro 1) de ADA no CB e na MPA indicam que esse uso e essa classe de solo, respectivamente, predispõem mais o solo à compactação, devido ao melhor arranjamento da massa do solo (Silva, 1997). Os maiores valores de IF foram encontrados no uso PD e UP e no MGX, sugerindo que essas áreas favorecem a manutenção da estrutura dos solos, já que a floculação é a primeira condição para a estabilização dos agregados.

Usando o método de Snedecor \& Cochran (1989), é possível verificar que os MCSCs para a MCX e para a MPA não mostraram diferenças (Quadro 2 e Figura 2 ), sendo, portanto, realizado um novo ajuste da equação com todos os valores de $\sigma_{p}$ e $\theta$, obtendo-se, assim, para ambos os solos, um novo MCSC, o qual passa a discutir o comportamento de $\sigma_{\mathrm{p}} \mathrm{e} \theta$, tanto para a MCX quanto para a MPA (Figura 3).

Esse novo MCSC obtido para a MCX e MPA, comparado com o MCSC para a MGX, difere estatisticamente, sugerindo, portanto, que o comportamento estrutural deve ser predito por seus respectivos modelos (Figura 3). O modelo ajustado para a MGX evidencia maior capacidade de suporte do que a MCX e MPA, isto é, foram observados maiores valores de $\sigma_{p}$ na MCX em relação às demais classes de solo (MCX e MPA) para um mesmo conteúdo de água. Isso deve-se principalmente aos maiores valores de matéria orgânica do solo (MOS) e IF encontrado nas áreas ocupadas por MGX, em comparação a MCX e MPA (Quadro 1). É sabido que a MOS promove maior agregação devido aos seus agentes cimentantes; essa melhor agregação também atua na preservação da MOS. Severiano et al. (2010b) também atribuíram ao teor de MOS a maior capacidade de suporte de carga do Cambissolo em comparação ao Latossolo.

Aplica-se também aos Gleissolos a explicação de que sua resistência não depende somente de sua textura ou de seu teor de matéria orgânica, mas também da livre entropia, que, durante repetidos ciclos de umedecimento e secagem, podem causar consideráveis mudanças na estrutura, resultando em melhor arranjamento de suas partículas nos agregados do solo (Horn \& Dexter, 1989).

A avaliação do impacto da pastagem nas classes de solo Cambissolo Háplico, Argissolo Amarelo e Gleissolo Háplico está apresentada na figura 4. No tocante ao impacto do uso da pastagem nas classes de solo (Figura 4), todas as amostras de solo para a PPA, nas duas condições de umidade, permaneceram na região em que não ocorreu compactação adicional do solo, porém há tendência de que venha a ocorrer caso não seja respeitada a capacidade de suporte de carga do solo. Todas as amostras sob alta umidade da PCX permaneceram na região $\mathrm{b}$, porém $6 \%$ das amostras em baixa umidade concentraram-se na região em que não há compactação (região c), 82 \% na região b e $12 \%$ 
Quadro 1. Caracterização do solo da camada de 0-5 cm, de diferentes tipos de manejo e classes de solo

\begin{tabular}{|c|c|c|c|c|c|c|c|c|c|}
\hline \multirow{2}{*}{ Variáveis } & \multicolumn{3}{|c|}{ Solos sob mata nativa } & \multicolumn{3}{|c|}{ Solos sob pastagem } & \multicolumn{3}{|c|}{ Cambissolo sob diversos usos } \\
\hline & MPA & MCX & MGX & PPA & PCX & PGX & UP & CB & PD \\
\hline $\mathrm{Dp}\left(\mathrm{kg} \mathrm{dm^{-3 } )}\right.$ & 2,59 & 2,67 & 2,36 & 2,56 & 2,65 & 2,62 & 2,56 & 2,65 & 2,60 \\
\hline $\mathrm{Ds}\left(\mathrm{Mg} \mathrm{m}^{-3}\right)$ & 1,19 & 1,14 & 0,88 & 1,24 & 1,32 & 1,20 & 1,39 & 1,28 & 1,47 \\
\hline $\mathrm{A}\left(\mathrm{g} \mathrm{kg}^{-1}\right)$ & 474 & 155 & 613 & 342 & 339 & 294 & 237 & 294 & 216 \\
\hline $\mathrm{S}\left(\mathrm{g} \mathrm{kg}^{-1}\right)$ & 127 & 343 & 258 & 229 & 221 & 468 & 122 & 317 & 146 \\
\hline $\mathrm{AF}\left(\mathrm{g} \mathrm{kg}^{-1}\right)$ & 267 & 6 & 88 & 208 & 217 & 72 & 186 & 232 & 212 \\
\hline $\mathrm{AG}\left(\mathrm{g} \mathrm{kg}^{-1}\right)$ & 131 & 495 & 41 & 220 & 223 & 166 & 455 & 157 & 426 \\
\hline $\mathrm{AT}\left(\mathrm{g} \mathrm{kg}^{-1}\right)$ & 398 & 502 & 129 & 429 & 440 & 238 & 641 & 389 & 638 \\
\hline $\mathrm{ADA}\left(\mathrm{g} \mathrm{kg}^{-1}\right)$ & 148 & 51 & 84 & 86 & 109 & 102 & 22 & 121 & 27 \\
\hline IF (\%) & 69 & 67 & 86 & 75 & 69 & 65 & 91 & 59 & 88 \\
\hline MO $\left(\mathrm{g} \mathrm{kg}^{-1}\right)$ & 29 & 25 & 49 & 53 & 35 & 23 & 45 & 36 & 33 \\
\hline
\end{tabular}

MPA: mata em Argissolo Amarelo; MCX: mata em Cambissolo Háplico; MGX: mata em Gleissolo Háplico; PPA: pastagem em Argissolo Amarelo; PCX: pastagem em Cambissolo Háplico; PGX: pastagem em Gleissolo Háplico; UP: uso silvipastoril; PD: pastagem degradada; CB: cultivo de banana; Dp: densidade de partículas; Ds: densidade do solo; A: argila; S: silte; AT: areia total; AG: areia grossa; AF: areia fina; ADA: argila dispersa em água; IF: índice de floculação; MO: teor de matéria orgânica. Média de 20 repetições.

Quadro 2. Teste de significância, segundo Snedecor \& Cochran (1989), entre os modelos de capacidade de suporte de carga para as diferentes classes de solos

\begin{tabular}{cccc}
\hline Solo & F & $\begin{array}{c}\text { Coeficiente } \\
\text { angular, b }\end{array}$ & $\begin{array}{c}\text { Coeficiente } \\
\text { linear, a }\end{array}$ \\
\hline MCX vs. MGX & NH & NS & $* *$ \\
MPA vs. MGX & NH & NS & $* *$ \\
MCX vs. MPA & H & NS & NS \\
MCX e MPA vs. MGX & NH & NS & $* *$ \\
\hline
\end{tabular}

NH: não homogêneo; H: homogêneo, $* *$ : significativo $(p<0,01)$ e NS: não significativo.

estavam compactadas (região a). As amostras de PGX em alta umidade permaneceram na sua grande maioria (80 \%) na região b, e as demais (20\%) não mostraram compactação. Em baixa umidade a situação foi ainda melhor, pois mais da metade (53\%) das amostras avaliadas não apresentou compactação, e o restante ( $47 \%$ ) permaneceu na região b.

A pressão de preconsolidação, além de representar a capacidade de suporte de carga de um solo, representa também o grau de estruturação dele (Severiano et al., 2008). Considerando a mata natural como uma referência em qualidade estrutural, os solos sob pastagem apresentaram maior capacidade de suporte de carga em relação à mata nativa, verificando-se assim o impacto das pastagens nesses solos de APPs. É relatado por Dias Júnior (2000) que diferentes sistemas de manejo podem gerar diferentes níveis de compactação em função da classe de solo. As maiores diferenças nas pressões de preconsolidação entre pastagem e mata nativa neste estudo foram evidenciadas no Cambissolo e no Argissolo. Em alta

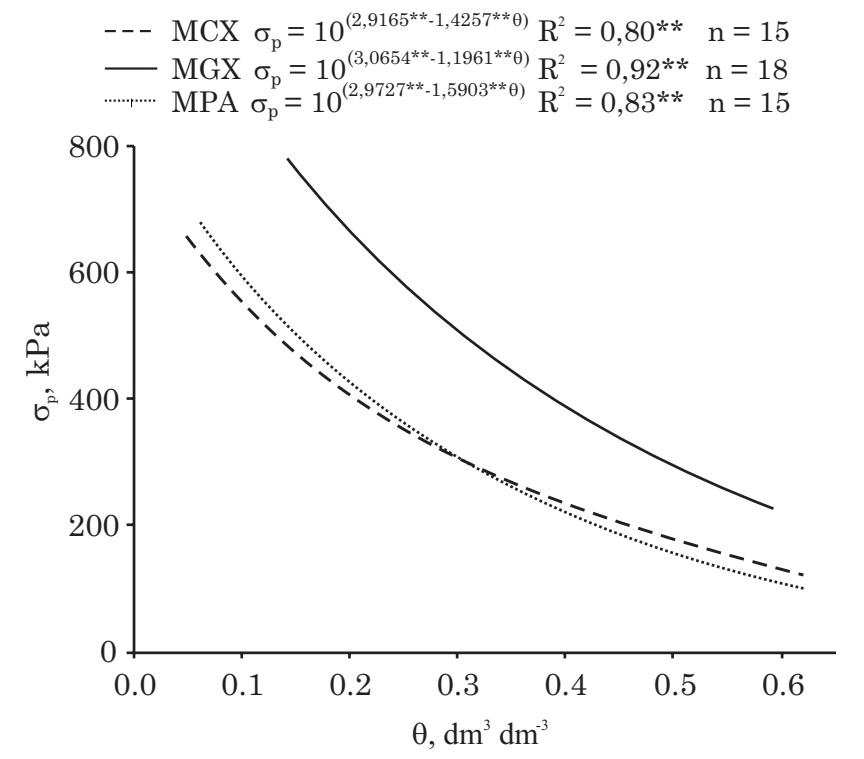

Figura 2. Modelos de capacidade de suporte de carga para um Gleissolo Háplico (MGX), Argissolo Amarelo (MPA) e Cambissolo Háplico (MCX), todos sob mata nativa, na camada de 0-5 cm, em APPs no município de Registro (SP).

umidade (Figura 5a), houve diferença entre pastagem e mata nativa nas três classes de solo avaliadas. Entre as pastagens, PCX e PPA mostraram comportamento semelhante e inferior em relação à PGX.

Nas amostras equilibradas em baixa umidade (Figura 5b), a pressão de preconsolidação mostrou diferenças entre pastagens e mata nativa somente para o Cambissolo e o Gleissolo. Para este último, os solos sob mata nativa mostraram maior capacidade de suporte que a pastagem, devido principalmente ao 


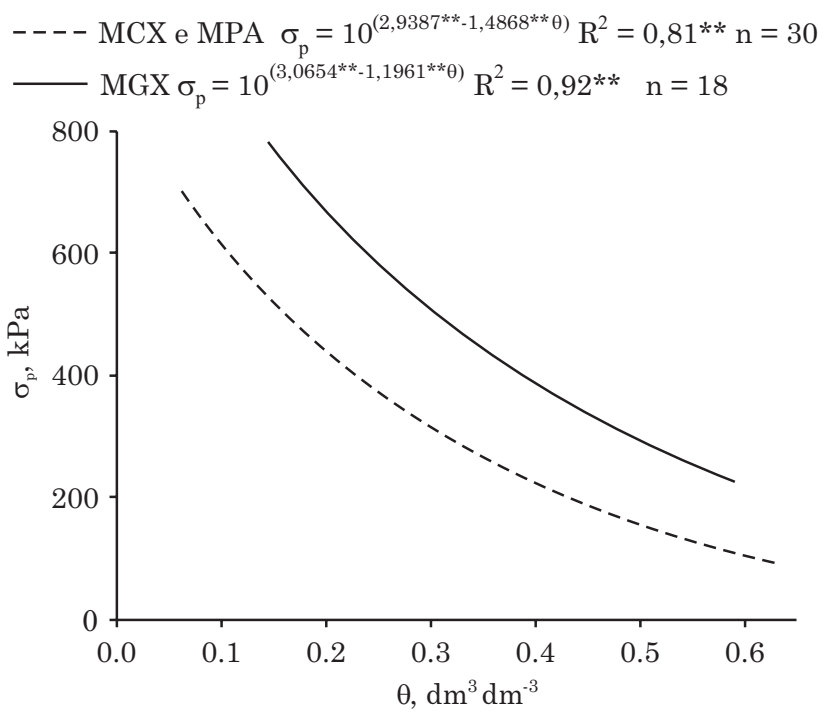

Figura 3. Novo modelo de capacidade de suporte de carga ajustado para o Argissolo (MPA) e Cambissolo (MCX) e modelo de capacidade de suporte de carga para um Gleissolo (MGX).

elevado teor de argila, o que, em baixas umidades, representou maior coesão entre essas partículas em relação ao mesmo solo sob pastagem. Entre as pastagens, as três classes de solo comportaram-se de maneira semelhante, por pertencerem a um mesmo grupamento textural (Embrapa, 2006).

É apresentada na figura 6 a avaliação do impacto dos três usos analisados num Cambissolo com amostras de solos equilibradas em alta e baixa umidade. Os três usos mostraram a maioria dos valores de $\sigma_{p}$ de suas amostras (Figura 6), compreendidas na região $\mathrm{b}$, indicando que não ocorreu compactação adicional do solo. Contudo, há uma tendência de que isso ocorra se não for respeitada a capacidade de suporte de carga do solo, juntamente com sua umidade crítica, sendo o uso CB ligeiramente mais crítico. Esses resultados sugerem o que ocorre em épocas de maior umidade no solo, comuns na região devido às altíssimas precipitações em determinadas épocas do ano (Silva et al., 2009). Para as amostras equilibradas a $13 \%$ de umidade, o uso UP mostrou $5 \%$ de suas amostras na região c, indicando que não ocorreu compactação do solo. O uso CB apresentou $10 \%$ de suas amostras na região a, ou seja, a compactação adicional já ocorreu. As amostras do uso PD apresentaram-se, em sua totalidade, compreendidas na região b.

A comparação da $\sigma_{p}$ dos tipos de uso revela que a maior capacidade de suporte de carga em solos equilibrados com alta umidade (Figura 7a) foi verificada nos três usos do solo, em relação à mata nativa (MCX).

O pisoteio animal influencia a capacidade de suporte de carga em solos, principalmente na camada superficial (Pires, 2007). Neste trabalho foi observada uma resistência maior à compactação na PD em relação ao UP. Esse comportamento deu-se pela menor intensidade de pisoteio dos animais dentro da mata, pois a circulação dos animais nesses locais é menor
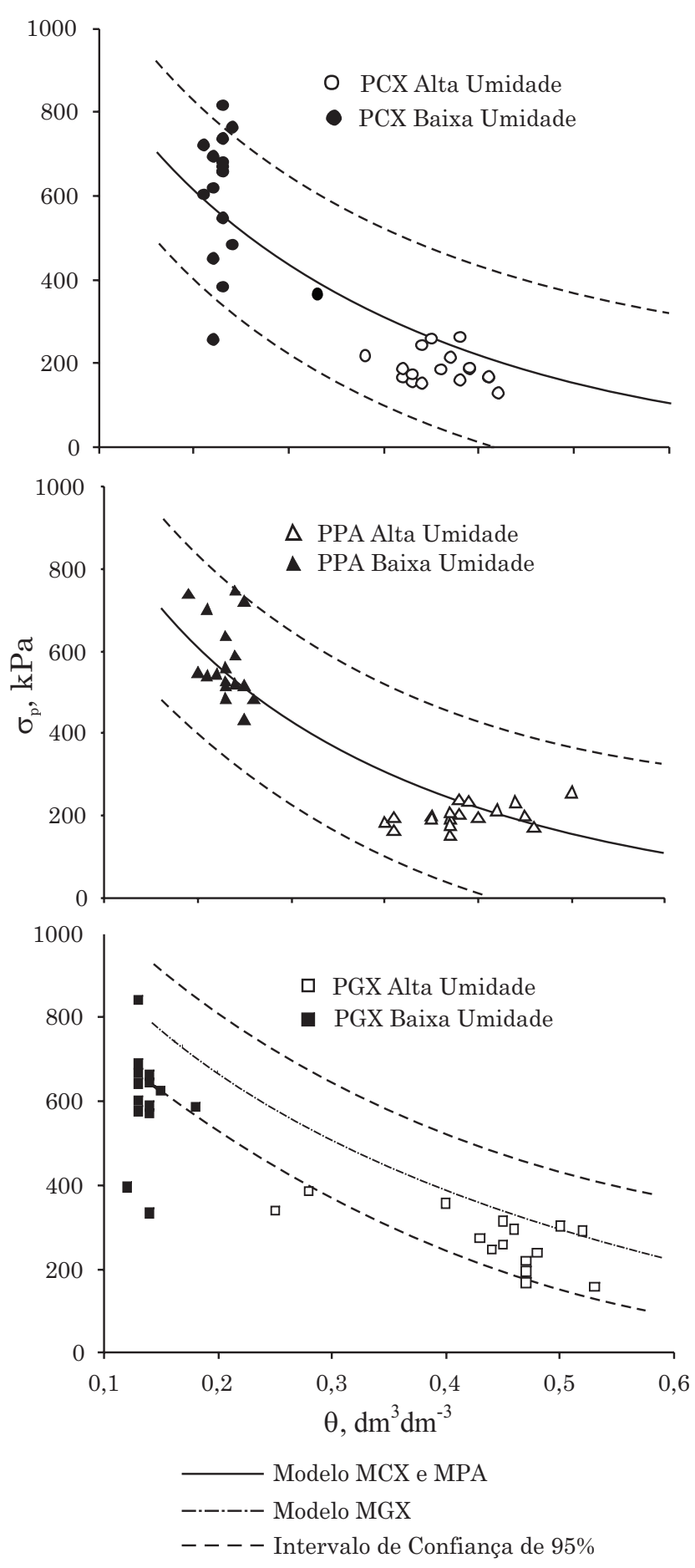

Figura 4. Modelos de capacidade de suporte de carga descrevendo o impacto da pastagem em amostras de solo equilibradas em alta e baixa umidade, para MCX, MPA e MGX. 


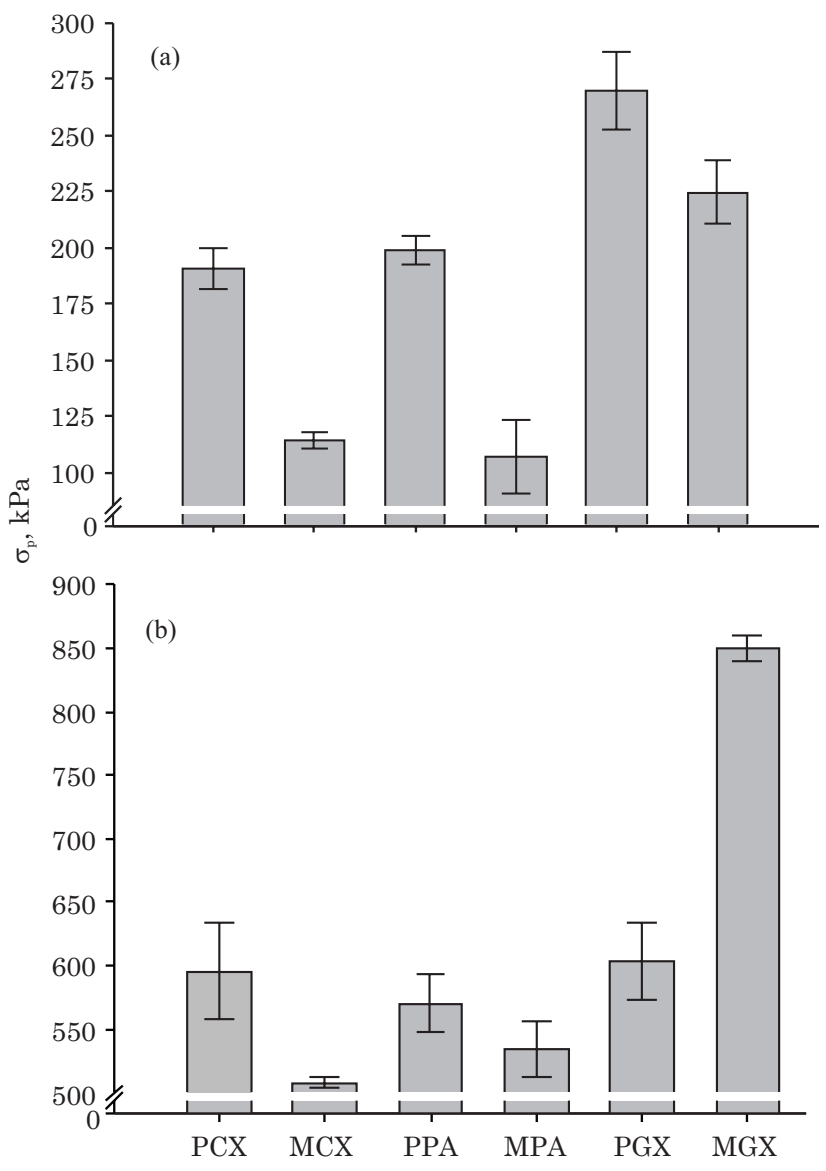

Figura 5. Médias da pressão de preconsolidação $\left(\sigma_{\mathrm{p}}\right)$ de amostras de solo equilibradas em alta umidade (a) e baixa umidade (b), para os usos, mata e pastagem em Cambissolo Háplico, Argissolo Amarelo e Gleissolo Háplico. A barra de erros representa o erro-padrão da média.

em relação ao PD. A carga estática exercida pelos bovinos foi estimada por Watkin \& Clements (1978) como variável entre 112 e $165 \mathrm{kPa}$; durante a movimentação do gado ela se multiplica, sendo consideravelmente maior. Comparando a pressão do pisoteio de gado em relação à pressão exercida por um trator (92 kPa), Souza et al. (1998) verificaram uma estimativa de aumento de $106 \%$ entre o pisoteio bovino e a pressão do trator.

O uso CB e a referência MCX não foram diferentes entre si, mas foram superiores aos outros dois usos, PD e UP, ou seja, mostraram maior capacidade de suporte de carga, em baixa umidade (Figura 7b). Estes usos (CB e MCX) mostraram maiores somas dos teores de argila e silte no solo, tornando-os mais coesos, em relação à $\mathrm{PD}$ e ao UP. É sabido que a coesão é resultante, no caso dessas partículas, de forças internas de natureza elétrica gerada entre as partículas, de modo que nessa condição de umidade a adesão é mínima, sendo a coesão favorecida, o que
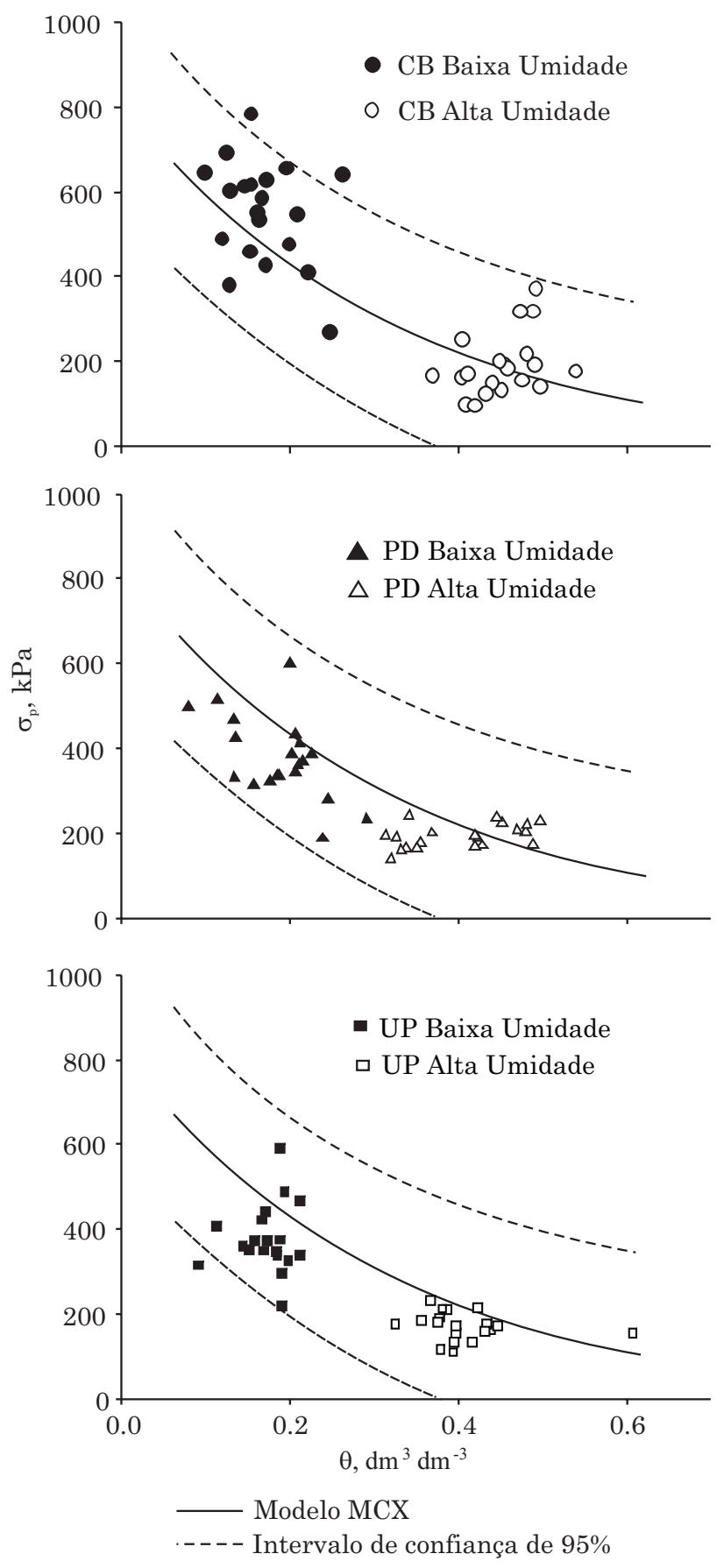

Figura 6. Modelos de capacidade de suporte de carga descrevendo o impacto dos três usos analisados em Cambissolo Háplico, com amostras equilibradas em alta e baixa umidade.

resulta em maior capacidade de suporte de carga. Esse comportamento não foi evidenciado nas amostras equilibradas em alta umidade, pois a coesão diminui com o aumento do teor de umidade, o que, por sua vez, pela maior presença de água nos interstícios, tende a diminuir as forças de natureza elétrica (Emmer, 2004). 


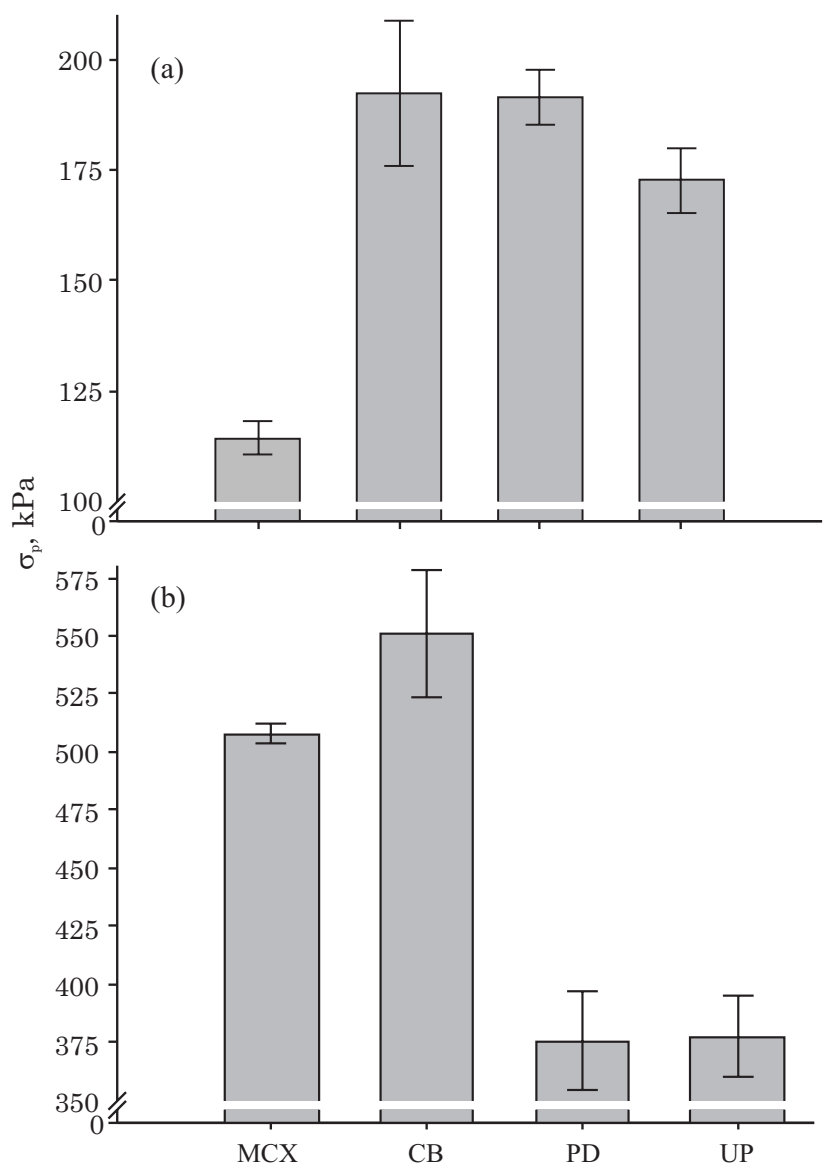

Figura 7. Médias da pressão de preconsolidação $\left(\sigma_{p}\right)$ equilibradas em alta umidade (a) e baixa umidade (b) para os diferentes tipos de uso em um Cambissolo Háplico. A barra de erros representa o erro-padrão da média.

$\mathrm{O}$ CB foi o tipo de uso do solo que mostrou maiores valores de $\sigma_{\mathrm{p}}$, configurando-se maior capacidade de suporte de carga no solo. Essa alta resistência à compressão e, portanto, esse maior grau de compactação eram esperados, pois as operações de manejo e colheita são realizadas em sua totalidade manualmente e não são respeitadas as condições ideais de umidade do solo. Segundo Lull (1959), o pisoteio humano proporciona pressões da ordem de $190 \mathrm{kPa}$ - valor esse superior ao de implementos de preparo do solo $(100 \mathrm{kPa}$, de acordo com Hillel, 1982), por exemplo. Na época de colheita da banana o impacto no solo é agravado, pois somam-se ao peso dos carregadores os dos cachos de banana, aumentando os valores de pressão exercida no solo.

\section{CONCLUSÕES}

1. A pressão de preconsolidação mostrou ser uma ferramenta capaz de identificar a real degradação nos solos.
2. O uso do solo nas áreas de preservação permanente altera a pressão de preconsolidação do solo, causando sua degradação estrutural, o que coloca em risco a sustentabilidade das terras, e não deve ser permitido.

3. Entre as classes de solo analisadas, a capacidade de suporte de carga para o Gleissolo foi maior que a do Cambissolo e a do Argissolo.

4. Dos usos do solo analisados, o cultivo de banana foi o que mais favoreceu a degradação dos solos das áreas de preservação permanente.

\section{LITERATURA CITADA}

AJAYI, A.E.; DIAS JÚNIOR, M.S.; CURI, N.; OKUNOLA, A.; TEIXEIRA SOUZA, T.T.T. \& PIRES, B.S. Assessment of vulnerability of Oxisols to compaction in the Cerrado Region of Brazil. Pedosphere, 20:252-260, 2010.

ARAÚJO-JÚNIOR, C.F.; DIAS JÚNIOR, M.S. \& GUIMARÃES, P.T.G. Resistência à compactação de um Latossolo cultivado com cafeeiro, sob diferentes sistemas de manejo de plantas invasoras. R. Bras. Ci. Solo, 32:23-32, 2008.

BAVER, L.D.; GARDNER, W.H. \& GARDNER, W.R. Soil physics. New York, John Wiley, 1972. 498p.

BLAKE, G.R. \& HARTGE, K.H. Bulk density. In: KLUTE, A., ed. Methods of soil analysis. Madison, Soil Science Society of America/American Society of Agronomy, 1986. Part 1. p.363-375.

BOCHNER, J.K. Serviços ambientais gerados pela floresta de mata Atlântica na qualidade do solo. Seropédica, Universidade Federal Rural do Rio de Janeiro, 2007. 45p. (monografia)

DAY, P.R. Particle fractionation and particle-size analysis. In: BLACK, C.A., ed. Methods of soil analysis. Madison, American Society of Agronomy, 1965. Part I. p.545-567. (Agronomy Monograph, 9)

DIAS JÚNIOR, M.S. Compression of three soils under longterm tillage and wheel traffic. East Lansing, Michigan State University, 1994. 114p. (Tese de Doutorado)

DIAS JÚNIOR, M.S. Compactação do solo. In: NOVAIS, R.F.; ALVAREZ V., V.H. \& SCHAEFER, C.E.G.R., eds. Tópicos em ciência do solo. Viçosa, MG, Universidade Federal de Viçosa, v. 1, 2000. p.55-94.

DIAS JÚNIOR, M.S.; LEITE, F.P.; LASMAR JÚNIOR, E. \& ARAUJO-JÚNIOR, C.F. Traffic effects on the soil preconsolidation pressure due to eucalyptus harvest operations. Sci. Agric., 62:248-255, 2005.

DIAS JÚNIOR, M.S. \& PIERCE, F.J. A simple procedure for estimating preconsolidation pressure from soil compression curves. Soil Technol., 8:139-151, 1995.

DIAS JÚNIOR, M.S.; SILVA, A.R.; FONSECA, S. \& LEITE, F.P. Método alternativo de avaliação da pressão de preconsolidação por meio de um penetrômetro. R. Bras. Ci. Solo, 28:805-810, 2004. 
DORAN, J.W. \& PARKIN, T.B. Quantitative indicators of soil quality: A minimum data set. In: DORAN, J.W. \& JONES, A.J., eds. Methods for assessing soil quality. Madison, Soil Science Society of America, 1996. p.25-37. (SSSA Special Publication, 49)

EMPRESA BRASILEIRA DE PESQUISA AGROPECUÁRIA EMBRAPA. Centro Nacional de Pesquisa de Solos. Manual de métodos de análises de solo. 2.ed. Rio de Janeiro, 1997. 212p.

EMPRESA BRASILEIRA DE PESQUISA AGROPECUÁRIA EMBRAPA. Centro Nacional de Pesquisa de Solos. Sistema brasileiro de classificação de solos. 2.ed. Rio de Janeiro, 2006. 306p.

EMMER, R. Implantação do campo experimental de Engenharia Geotécnica da UFSM. Santa Maria, Universidade Federal de Santa Maria, 2004. 191p. (Tese de Mestrado)

FERREIRA, D.F. Manual do sistema Sisvar para análises estatísticas. Lavras, Universidade Federal de Lavras, 2000. 66p.

HILLEL, D. Introduction to soil physics. San Diego, Academic Press, 1982. 364p.

HORN, R. \& DEXTER, A.R. Dynamics of soil aggregation in a homogenized desert loess. Soil Tillage Res., 13:254-266, 1989.

LAL, R. Métodos para a avaliação do uso sustentável dos recursos solo e água nos trópicos. Jaguariúna, Embrapa Meio Ambiente, 1999. 97p. (Embrapa Meio Ambiente. Documentos, 3)

LOPES, M.M. Efeito do pastoreio rotativo nos indicadores químicos, físicos e biológicos de um Latossolo Vermelho Amarelo, no município de Teresina. Teresina, Universidade Federal do Piauí, 2007. 38p. (Tese de Mestrado)

LULL, H.W. Soil compaction on forest and range lands. Washington, Forest Service United States Department of Agriculture, 1959. 33p. (Miscellaneous Publication, 768).

OLIVEIRA, G.C.; DIAS JÚNIOR, M.S.; RESCK, D.V.S. \& CURI, N. Alterações estruturais e comportamento compressivo de um Latossolo Vermelho distrófico argiloso sob diferentes sistemas de uso e manejo. Pesq. Agropec. Bras., 38:291-299, 2003.

PAES, A.T. Por dentro da estatística. Einstein: Educ. Contin. Saúde, 6:107-108, 2008.

PIRES, B. Resistência ao cisalhamento e compressibilidade de um Latossolo sob diferentes usos e manejos. Lavras, Universidade Federal de Lavras, 2007. 86p. (Tese de Mestrado)

PRIMAVESI, A. Manejo ecológico do solo: A agricultura em regiões tropicais. São Paulo, Nobel, 2002. 549p.

RÖMKENS, M.J.M. \& MILLER, R.D. Predicting root size and frequency from one-dimensional consolidation data - a mathematical model. Plant Soil, 248:237-248, 1971.

SEVERIANO, E.C.; OLIVEIRA, G.C.; DIAS JÚNIOR, M.S.; OLIVEIRA, L.F.C. \& CASTRO, M.B. Pressão de preconsolidação e intervalo hídrico ótimo como indicadores de alterações estruturais do solo em decorrência das operações de colheita da cana-de-açúcar. R. Bras. Ci. Solo, 32:1419-1427, 2008.
SEVERIANO, E.C.; OLIVEIRA, G.C.; DIAS JÚNIOR, M.S.; CASTRO, M.B.; OLIVEIRA, L.C. \& COSTA, K.A.P. Compactação de solos cultivados com cana-de-açúcar: Imodelagem e quantificação da compactação adicional após as operações de colheita. Eng. Agríc., 30:404-413, 2010a.

SEVERIANO, E.C.; OLIVEIRA, G.C.; DIAS JÚNIOR, M.S.; CASTRO, M.B.; OLIVEIRA, L.C. \& COSTA, K.A.P. Compactação de solos cultivados com cana-de-açúcar: IIquantificação das restrições às funções edáficas do solo em decorrência da compactação prejudicial. Eng. Agríc., 30:414-423, 2010b.

SILVA, A.P. Distribuição de poros de Argissolo VermelhoAmarelo sob pomares de laranja: uma abordagem multivariada. In: CONGRESSO BRASILEIRO DE CIÊNCIA DO SOLO, 26., Rio de Janeiro, 1997. Anais... Rio de Janeiro, Universidade Federal do Rio de Janeiro, 1997. CD-ROM

SILVA, R.B.; DIAS JÚNIOR, M.S.; SILVA, F.A.M. \& FOLE, S.M. O tráfego de máquinas agrícolas e as propriedades físicas, hídricas e mecânicas de um Latossolo dos Cerrados. R. Bras. Ci. Solo, 27:973-983, 2003.

SILVA, R.B.; IORI, P. \& SILVA, F.A.M. Proposição e validações de equações para estimativa da erosividade de dois municípios do estado de São Paulo. Irriga, 14:533-547, 2009.

SILVA, R.B.; IORI, P.; SILVA, F.A.M. \& DIAS JÚNIOR, M.S. Modelagem e determinação do estado crítico de consolidação a partir da relação massa e volume em solos canavieiros. R. Ci. Agrar., 33:376-389, 2010a.

SILVA, R.B.; IORI, P.; ARMESTO, C. \& BENDINI, H.N. Assessing rainfall erosivity with artificial neural networks for the Ribeira Valley, Brazil. Intern. J. Agron., 2010:1-7, 2010 b.

SILVA, R.B.; LANÇAS, K.P. \& MASQUETTO, B.J. Consolidômetro: Equipamento pneumático-eletrônico para avaliação do estado de consolidação do solo. R. Bras. Ci. Solo, 31:617-615, 2007.

SILVA, R.B. \& MASQUETTO, B.J. CA-Linker: Sistema para monitoramento, aquisição e processamento de parâmetros físicos e mecânicos em tempo real, gerados em ensaios de consolidação uniaxial. In: CONGRESSO BRASILEIRO DE CIÊNCIA DO SOLO, 32., Fortaleza, 2009. Anais... Fortaleza, Universidade Federal do Ceará, 2009. CD-ROM

SNEDECOR, G.W. \& COCHRAN, W.G. Statistical methods. 8.ed. Ames, Iowa State University Press, 1989. 503p.

SOUZA, A.R.; SILVA, A.B. \& RESENDE, M. Influência da pressão exercida por pisoteio de animais na compactação do solo do vale do Pajeú, em Pernambuco. In: REUNIÃO BRASILEIRA DE MANEJO E CONSERVAÇÃO DO SOLO DA ÁGUA, 12., Fortaleza, 1998. Anais... Fortaleza, Sociedade Brasileira de Ciência do Solo, 1998. p.256-257.

TAYLOR, D.W. Fundamentals of soil mechanics. New York, John Wiley, 1948. 770p.

WATKIN, B.R. \& CLEMENTS, R.J. The effects of grazing animals on pastures. In: WILSON, J.R., ed. Plant relations in pastures. Melbourne, CSIRO, 1978. p.273-289. 